\title{
ChemComm
}

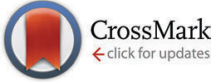

Cite this: Chem. Commun., 2016, 52,8115

Received 19th April 2016, Accepted 25th May 2016

DOI: $10.1039 / c 6 c c 03289 c$

www.rsc.org/chemcomm

\section{2-Methylresorcinarene: a very high packing coefficient in a mono-anion based dimeric capsule and the X-ray crystal structure of the tetra-anion $\dagger$}

\author{
Rakesh Puttreddy, ${ }^{a}$ Ngong Kodiah Beyeh, ${ }^{b}$ Elina Kalenius, ${ }^{a}$ Robin H. A. Ras ${ }^{b}$ and \\ Kari Rissanen*a
}

Mono- and tetra-deprotonated 2-methylresorcinarene anions (1 and 2) as their trans-1,4-diammoniumcyclohexane $(T D A C)^{2+}$ inclusion complexes are reported. The mono-anion forms a fully closed dimeric capsule $\left[1 \cdot \mathrm{H}_{2} \mathrm{O} \cdot \mathrm{MeOH}\right]_{2}{ }^{2-}$ with a cavity volume of $165 \AA^{3}$ and (TDAC) ${ }^{2+}$ as the guest with an extremely high packing coefficient, $P C=84.2 \%$, while the tetra-anion forms a close-packed structure with two structurally isomeric tetra-anions $2 \mathrm{a}$ and $2 \mathrm{~b}$ with a $50: 50$ ratio in the crystal lattice.

Resorcinarenes are stable $\pi$-rich cavity containing host systems in the $C_{4 \mathrm{v}}$ crown conformation. ${ }^{1}$ Since the 1980 's, resorcinarenes and their cavitand analogues have played a key role in molecular recognition processes in a multitude of host-guest systems. ${ }^{2}$ The easy synthesis and selective functionalization either at the upper rim hydroxyl groups or the 2-position on the aromatic rings, and the lower rims have made them a very useful and accessible family of host compounds. ${ }^{2}$ With the $C_{4 v}$ vase shaped cavity, resorcinarenes manifest selective guest complexation and in some cases encapsulation through a multitude of weak non-covalent interactions such as cation $\cdots \pi, \mathrm{C}-\mathrm{H} \cdots \pi$ and $\pi \cdots \pi$ interactions. ${ }^{3}$ In addition, the hydroxyl groups form strong hydrogen bonds with exo- or endo-complexed guests in the solid state. ${ }^{3}$ The construction of hydrogen bond based host-guest systems using resorcinarenes has been well-studied with alcohols, ${ }^{4}$ sugars ${ }^{5}$ steroids, ${ }^{6}$ as well as with heterocyclic five- and sixmembered ring compounds. ${ }^{7}$

Treating core resorcinarenes with even weak bases ${ }^{8}$ leads to the formation of deprotonated species in which the increased $\pi$-character of the resorcinarene cavity can be used for more efficient molecular recognition processes by enhancing the weak interactions. ${ }^{9}$ In resorcinarenes, the acidity of the first

\footnotetext{
${ }^{a}$ University of Jyvaskyla, Department of Chemistry, Nanoscience Center, P.O. Box 35, FI-40014, Finland. E-mail: kari.t.rissanen@jyu.fi

${ }^{b}$ Aalto University, Department of Applied Physics, Puumiehenkuja 2, 02150 Espoo, Finland

$\dagger$ Electronic supplementary information (ESI) available: Single crystal experimental details and mass spectrometry data are included. CCDC 1473236 and 1473237. For ESI and crystallographic data in CIF or other electronic format see DOI: $10.1039 / \mathrm{c} 6 \mathrm{cc} 03289 \mathrm{c}$
}

proton is greater than that of the second and so on, and the cavity attains maximum stability upon tetra-deprotonation, retaining its crown $C_{4 \mathrm{v}}$ conformation, and being stabilized by stronger circular intramolecular $\mathrm{O}-\mathrm{H} \cdots \mathrm{O}^{-}$hydrogen bonds. The tetra-deprotonated resorcinarenes viz. tetraphenolate anions are known to exist in alkaline media, and are reported to have remarkably high binding constants towards alkyl ammonium salts when compared to the neutral non-deprotonated resorcinarenes. ${ }^{10}$ The strong electrostatic interactions between the $\pi$-delocalized negatively charged macrocyclic cavity and cationic guests have been reported to lead to high binding constants. ${ }^{9}$ Schneider and co-workers demonstrated the hydrolysis of acetylcholine to choline in the resorcinarene tetraphenolate cavity by ${ }^{1} \mathrm{H} \mathrm{NMR}$, supporting the hydrolysis mechanism with molecular models. ${ }^{11}$ Other biological molecules have also been hosted by the resorcinarene tetraphenolate. ${ }^{12}$

Although the resorcinarene tetraphenolate is known in solution, the crystal structure of it has remained elusive. Along these lines, we have previously reported the structures of monoand di-deprotonated core resorcinarenes using mono- and diamine bases in the solid state. ${ }^{13}$ In this contribution, we report the preparation, X-ray crystal structures and the electrospray ionization mass spectrometry (ESI-MS) characterization of mono- (1) and tetra-anions (2) as their trans-1,4-diammoniumcyclohexane, (TDAC) ${ }^{2+}$, complexes obtained by reacting 2-methylresorcinarene, 2-MeC2, and trans-1,4-diaminocyclohexane, TDAC, as shown in Fig. 1.

Single crystals of the complexes (TDAC) ${ }^{\mathbf{2}} @\left[\mathbf{1} \cdot \mathrm{H}_{2} \mathrm{O} \cdot \mathrm{MeOH}\right]_{2}$ and $2(2) \cdot 3(\text { TDAC })^{2+} \cdot 2(\text { TDAC })^{+} \cdot 15(\mathrm{MeOH}) \cdot 0.5\left(\mathrm{H}_{2} \mathrm{O}\right)$ were prepared by mixing $1: 1$ and $1: 4$ molar ratios of 2 -MeC2 and TDAC in methanol, respectively, followed by slow evaporation at room temperature. The reaction of 2-MeC2 and TDAC in a 1:1 molar ratio forms a tight neutral hydrogen bonded capsule, (TDAC) $^{2+} @\left[\mathbf{1} \cdot \mathrm{H}_{2} \mathrm{O} \cdot \mathrm{MeOH}\right]_{2}$, where the cavity entraps (TDAC) ${ }^{2+}$, as the guest, as shown in Fig. 2. In this dimeric capsule, the capsule halves are held tightly together by hydrogen bonds via two methanol $\left[(\mathrm{O}-\mathrm{H})_{\text {host }} \cdots(\mathrm{O})_{\mathrm{MeOH}} \cdots(\mathrm{H}-\mathrm{O})_{\text {host }}\right]$ and two water molecules $\left[(\mathrm{O}-\mathrm{H})_{\text {host }} \cdots(\mathrm{O}-\mathrm{H})_{\text {water }} \cdot(\mathrm{O}-\mathrm{H})_{\text {host }}\right]$. The endo-cavity $(\text { TDAC })^{2+}$ is encapsulated very tightly via additional $\mathrm{N}-\mathrm{H} \cdots \mathrm{O}$ 


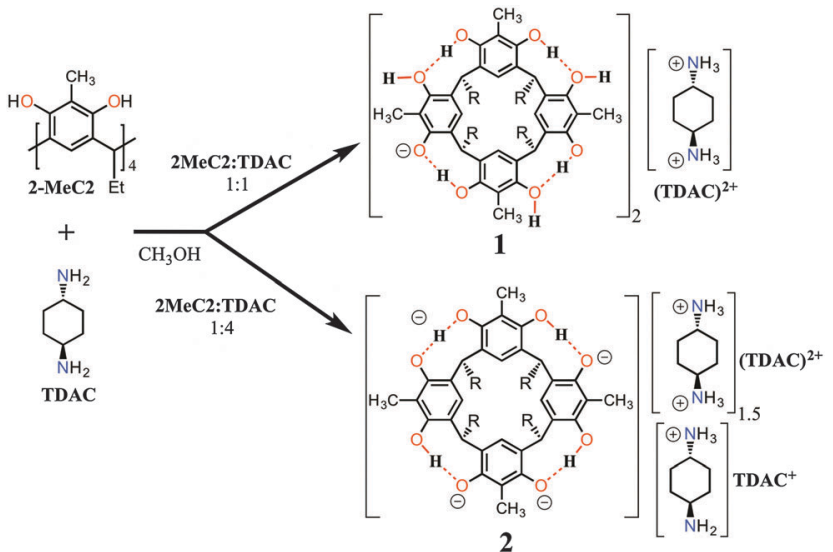

Fig. 1 Synthesis of mono- (1) and tetra-anions (2) from 2-methylresorcinarene (2-MeC2) and trans-1,4-diaminocyclohexane (TDAC). Nomenclature: TDAC $=$ trans-1,4-diaminocyclohexane; $(\text { TDAC })^{+}=$trans 1-ammonium-4-aminocyclohexane; (TDAC) $)^{2+}=$ trans-1,4-diammoniumcyclohexane.

and $\mathrm{N}-\mathrm{H} \cdots \pi$ interactions to the hosting capsule (see ESI, $\dagger$ Fig. S3a). These concerted guest-to-host interactions resulted in an extremely high packing coefficient (PC) of 0.842 , viz. $84.2 \%$. The volume of 3 , 138.9 $\AA^{3}$, was obtained using Spartan ${ }^{14}$ at MM level, while the cavity volume, $165 \AA^{3}$, was calculated using MSroll $^{15}$ within X-Seed ${ }^{16}$ with a $1.2 \AA$ probe, $\mathrm{PC}=138.9 \AA^{3} / 165 \AA^{3}=0.842$.

Contrary to the mono-anion, the tetra-anion 2 is an open inclusion complex, with overall composition of $2(2) \cdot 3$ (TDAC) ${ }^{2+}$. 2TDAC ${ }^{+} \cdot 15(\mathrm{MeOH}) \cdot 0.5\left(\mathrm{H}_{2} \mathrm{O}\right)$, the eight negative charges being counterbalanced with two endo-cavity (TDAC) ${ }^{2+}$, one exo-cavity (TDAC) $^{2+}$ and two exo-cavity (TDAC) ${ }^{+}$cations. The deprotonation of the hydroxyl groups in 2-MeC2 can, from very high quality single crystal X-ray diffraction data, be observed from the residual electron density map [in the case of $\mathbf{1}$, all $\mathrm{H}$-atoms are clearly visible and this unambiguously confirms that one of the hydroxyl groups does not have a $\mathrm{H}$-atom in it, namely $\mathrm{O6}$ (see ESI, $\dagger$ Fig. S1)]. Another way, which is more reliable with lower quality data (as in case of 2), is the fact that a normal $\mathrm{OH}$ group both accepts and donates H-bonds, while a deprotonated, (a)

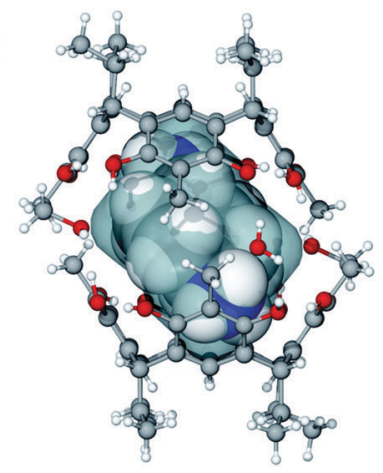

(b)

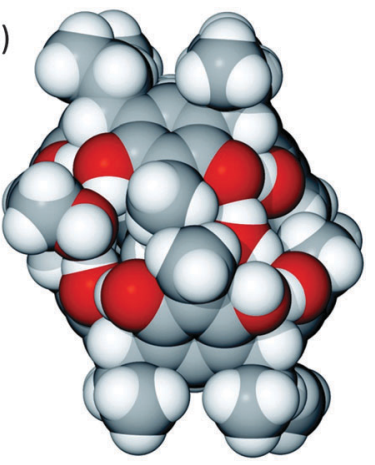

Fig. 2 Dimeric capsule, (TDAC) ${ }^{2+} \mathrm{a}\left[\mathbf{1} \cdot \mathrm{H}_{2} \mathrm{O} \cdot \mathrm{MeOH}\right]_{2}$ shown in (a) as ball and stick with the calculated cavity in transparent grey colour and the guest (TDAC) ${ }^{2+}$ as CPK to illustrate the very tight encapsulation and (b) as the CPK model.
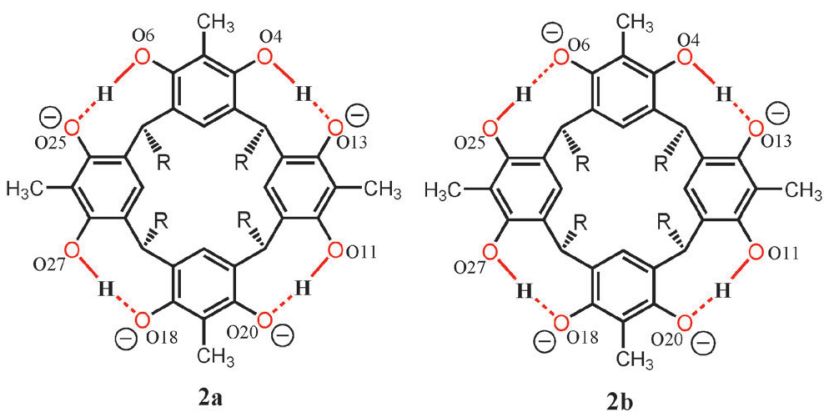

Fig. 3 Chemdraw representation of tetra-anions $\mathbf{2 a}$ and $\mathbf{2} \mathbf{b}$. The orientation of the resorcinarene core and the oxygen atoms are labelled as in the crystal structure shown in ESI, $\dagger$ Fig. S4.

viz. phenolate, group accepts three H-bonds. In the case of 2, this is unambiguously verified for the hydroxyl O-atoms O13, O20 and $\mathrm{O} 18$ (see ESI, $\dagger$ Fig. S4). While the O-atoms $\mathrm{O} 6$ and $\mathrm{O} 25$ show a disorder of the hydrogen atoms with a disordered methanol molecule hydrogen bonded to these two O-atoms. Closer inspection reveals that indeed the crystal lattice contains two distinct structural isomers for the tetra-anion 2, viz. $\mathbf{2 a}$ and $\mathbf{2 b}$, as represented by the 2-D drawings in Fig. 3. The two isomers crystallize so that every second unit cell contains $\mathbf{2 a}$ and $\mathbf{2 b}$ (see ESI, $\dagger$ Fig. S4 for crystal structures), thus manifesting positional $50: 50$ disorder within the same unit cell. However both $2 \mathrm{a}$ and 2b have the same orientation in the unit cell so that the oxygen atoms $\mathrm{O} 6(50 \%)$ and $\mathrm{O} 25(50 \%)$ accept three hydrogen bonds ${ }^{13}$ as shown in Fig. 3.

The following observations were used to ascertain the structure of the mono-anion $\mathbf{1}$ and the two structural isomers $\mathbf{2 a}$ and 2b of the tetra-anion:

(1) The hydrogen atom positions were located unambiguously from the electron density map for the protonated $-\mathrm{NH}_{3}{ }^{+}$ groups in the (TDAC) ${ }^{2+}$ and (TDAC) ${ }^{+}$cations for both 1 and 2 , as well as the upper rim $\mathrm{O}-\mathrm{H} \cdots \mathrm{O}^{-}$hydrogen bonds for $\mathbf{1}$ (see ESI, $\dagger$ Fig. S1 and S2).

(2) Deprotonated, viz. the phenolate, oxygen atoms act as triple hydrogen bond acceptors in both 1 and 2 .

(3) The oxygen atoms, O6 and O25, in the two structural isomers $\mathbf{2 a}$ and $\mathbf{2 b}$ were confirmed to act as triple hydrogen bond acceptors at 50:50 ratios through careful analysis of the similarly disordered methanol molecules hydrogen bonded to them.

The effect of TDAC on the deprotonation of 2-MeC2 in the gas phase was studied through a series of ESI-MS analyses in $\mathrm{MeCN} / \mathrm{MeOH}$. Titration experiments showed that the deprotonated charge states of 2-MeC2 increased until four equivalents of TDAC were added (Fig. 4a). The mono- and di-deprotonated ions, $[2-\mathbf{M e C} 2-\mathrm{H}]^{-}$and $[2-\mathbf{M e C 2}-2 \mathrm{H}]^{2-}$, were clearly observed in the ESI-MS spectra (see ESI, $\uparrow$ Fig. S5). Gas phase stability is known to be low for low molecular weight multiply charged ions in conditions where stabilizing solvent interactions are absent. ${ }^{17}$ Higher charge density, therefore, usually leads to coulombic explosion of the compound. Gas phase basicities for the multi-deprotonated ions $[2-\mathbf{M e C} 2-3 \mathrm{H}]^{3-}$ and $[2-\mathbf{M e C 2}-4 \mathrm{H}]^{4-}$, 
(a)

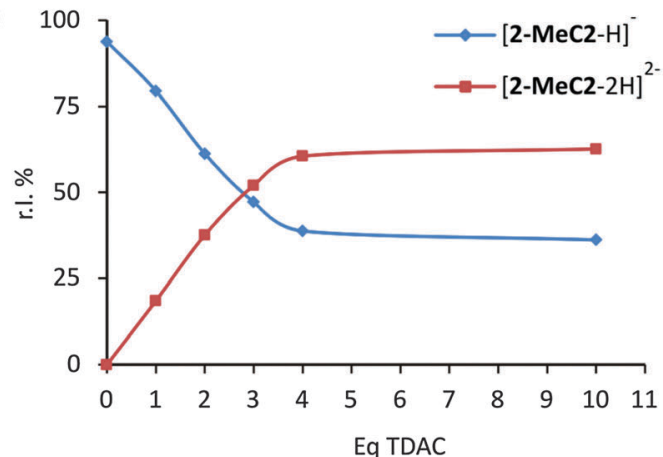

(b)

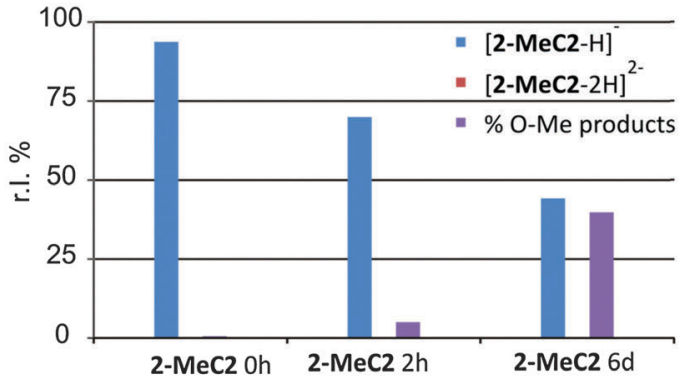

(c)

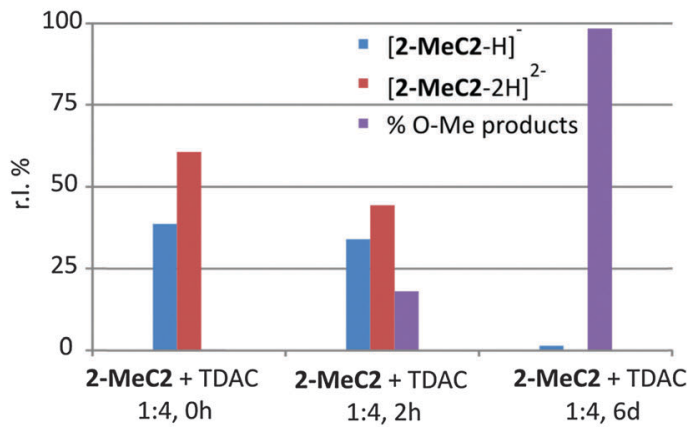

Fig. 4 (a) Relative intensities (r.i.\%) of deprotonated ions observed in (-)ESI-MS spectra as a function of added TDAC equivalents. Relative intensities (r.i.\%) of the deprotonated ions observed in (-)ESI-MS spectra in aged samples; (b) 2-MeC2 in MeCN: MeOH (25:1 v/v) and (c) 2-MeC2 and TDAC $1: 4$ in $\mathrm{MeCN}: \mathrm{MeOH}(25: 1 \mathrm{v} / \mathrm{v})$.

are assumed to be relatively high. Hence, the tri- and tetradeprotonated ions can easily abstract a proton from methanol, which originates from the $\mathrm{MeCN}: \mathrm{MeOH}(25: 1 \mathrm{v} / \mathrm{v})$ mixture used in the ESI-MS experiments due to too low solubility of TDAC in aprotic solvents. The stabilizing interactions between the deprotonated $\mathrm{OH}$ groups of the 2-MeC2 and TDAC molecules (which were present in the solid state structures) were not observed in gas phase measurements. However, interaction of the deprotonated ions with solvent molecules was clearly observed in time-dependent ESI-MS experiments, in which the samples of 2-MeC2 and 2-MeC2 + TDAC (1:4) were aged (Fig. 4b and c). The interaction of 2-MeC2 with methanol or acetonitrile resulted in mono- and di-O-methylation products and methanol adducts (see ESI, $\dagger$ Scheme S1). The characterization of the $O$-methylation products was verified by collision induced dissociation (CID) experiments (see ESI, † Fig. S6).

In conclusion, we have utilized a simple organic diamine, trans-1,4-diaminocyclohexane, TDAC, to deprotonate the 2-methyl-resorcinarene and were able to isolate the mono- and tetra-anions. The mono-anion 1 forms, with the help of two water molecules and two methanol molecules, an unprecedented fully closed and charge-neutral hydrogen bonded dimeric capsule which has an extremely high packing coefficient PC of $84.2 \%$ for the trans-1,4-diammoniumcyclohexane as the guest. The X-ray crystal structure of 2 not only proves the existence of the tetraanion in solid state, but reveals two structural isomers of it. The isomers, which occur in the same crystal lattice with a position of $50 \%$ occupancy each, show the same deprotonation pattern for the three hydroxyl groups and the difference between $\mathbf{2 a}$ and $\mathbf{2 b}$ occurring with the deprotonation of the fourth hydroxyl group at one "corner" of the resorcinarene skeleton in such a way that it does not affect the overall conformation of the tetra-anion, being $C_{4 \mathrm{v}}$ for both isomers.

We gratefully acknowledge the Academy of Finland (KR: grant no. 263256, 292746, NKB: grant no. 258653, EK: grant no. 284562, 278743, RHAR: grant no. 272579), University of Jyväskylä and Aalto University for financial support.

\section{References}

1 (a) P. Timmerman, W. Verboom and D. N. Reinhoudt, Tetrahedron, 1996, 52, 2663-2704; (b) W. Sliwa and C. Kozlowski, Calixarenes and Resorcinarenes, Wiley, 2009; (c) J. L. Atwood and A. Szumna, J. Supramol. Chem., 2002, 2, 479-482.

2 (a) D. Ajami, L. Liu and J. Rebek Jr., Chem. Soc. Rev., 2015, 44, 490-499; (b) K. Jie, Y. Zhou, Y. Yao and F. Huang, Chem. Soc. Rev., 2015, 44, 3568-3587; (c) T. S. Koblenz, J. Wassenaar and J. N. H. Reek, Chem. Soc. Rev., 2008, 37, 247-262; (d) A. Shivanyuk and J. Rebek, J. Am. Chem. Soc., 2003, 125, 3432-3433.

3 (a) J. L. Atwood and A. Szumna, Chem. Commun., 2003, 940-941; (b) J. L. Atwood, L. J. Barbour and A. Jerga, Proc. Natl. Acad. Sci. U. S. A., 2002, 99, 4837-4841; (c) L. R. MacGillivray and J. L. Atwood, Chem. Commun., 1999, 181-182; (d) A. Shivanyuk, E. F. Paulus, K. Rissanen, E. Kolehmainen and V. Böhmer, Chem. - Eur. J., 2001, 7, 1944-1951; (e) N. K. Beyeh, M. Kogej, A. Åhman, K. Rissanen and C. A. Schalley, Angew. Chem., Int. Ed., 2006, 45, 5214-5218.

4 (a) N. K. Beyeh, D. P. Weimann, L. Kaufmann, C. A. Schalley and K. Rissanen, Chem. - Eur. J., 2012, 18, 5552-5557; (b) L. Avram, Y. Cohen and J. Rebek Jr., Chem. Commun., 2011, 47, 5368-5375; (c) I. A. Koshets, Z. I. Kazantseva, A. E. Belyaev and V. I. Kalchenko, Sens. Actuators, B, 2009, 140, 104-108; (d) O. Ugono and K. T. Holman, Chem. Commun., 2006, 2144-2146; (e) O. D. Fox, J. F.-Y. Leung, J. M. Hunter, N. K. Dalley and R. G. Harrison, Inorg. Chem., 2000, 39, 783-790.

5 (a) E. Kalenius, T. Kekäläinen, R. Neitola, K. Beyeh, K. Rissanen and P. Vainiotalo, Chem. - Eur. J., 2008, 14, 5220-5228; (b) M. He, R. J. Johnson, J. O. Escobedo, P. A. Beck, K. K. Kim, N. N. S. Luce, C. J. Davis, P. T. Lewis, F. R. Fronczek, B. J. Melancon, A. A. Mrse, W. D. Treleaven and R. M. Strongin, J. Am. Chem. Soc., 2002, 124, 5000-5009; (c) T. Evan-Salem, I. Baruch, L. Avram, Y. Cohen, L. C. Palmer and J. Rebek, Proc. Natl. Acad. Sci. U. S. A., 2006, 103, 12296-12300; (d) T. Rhlalou, M. Ferhat, M. A. Frouji, D. Langevin, M. Métayer and J.-F. Verchère, J. Membr. Sci., 2000, 168, 63-73.

6 (a) A. Shivanyuk and J. Rebek, Chem. Commun., 2001, 2374-2375; (b) J. D. Faull and V. K. Gupta, Thin Solid Films, 2003, 440, 129-137; (c) J. D. Faull and V. K. Gupta, Langmuir, 2002, 18, 6584-6592.

7 (a) M. Nissinen, E. Wegelius, D. Falábu and K. Rissanen, CrystEngComm, 2000, 2, 151; (b) M. Nissinen and K. Rissanen, Supramol. Chem., 2003, 15, 581-590.

8 (a) A. Jasat and J. C. Sherman, Chem. Rev., 1999, 99, 931-968; (b) F. Farina, C. Talotta, C. Gaeta and P. Neri, Org. Lett., 2011, 13, 4842-4845, and references therein.

9 H.-J. Schneider, Angew. Chem., Int. Ed., 2009, 48, 3924-3977.

10 H.-J. Schneider, D. Güttes and U. Schneider, Angew. Chem., Int. Ed., 1986, 25, 647-649. 
11 (a) H.-J. Schneider and U. Schneider, J. Inclusion Phenom. Mol. Recognit. Chem., 1994, 19, 67-83; (b) H. J. Schneider, D. Guettes and U. Schneider, J. Am. Chem. Soc., 1988, 110, 6449-6454; (c) H. J. Schneider and U. Schneider, J. Org. Chem., 1987, 52, 1613-1615; (d) F. Weinelt and H. J. Schneider, J. Org. Chem., 1991, 56, 5527-5535.

12 M. Inouye, K. Hashimoto and K. Isagawa, J. Am. Chem. Soc., 1994, 116, $5517-5518$.
13 N. K. Beyeh, A. Valkonen and K. Rissanen, CrystEngComm, 2014, 16, 3758-3764.

14 Spartan'14, Wavefunction, Inc., Irvine, USA.

15 M. L. Connolly, J. Mol. Graphics, 1993, 11, 139-141.

16 (a) L. J. Barbour, J. Supramol. Chem., 2001, 1, 189-191; (b) J. L. Atwood and L. J. Barbour, Cryst. Growth Des., 2003, 3, 3-8.

17 R. B. Cole, Electrospray Ionization Mass Spectrometry: Fundamentals, Instrumentation \& Applications, Wiley, New York, 1997, pp. 137-174. 